\title{
Helping Hands or Comforting the Soul?
}

\author{
Maria Colon-Gonzalez ${ }^{a}$
}

\begin{abstract}
${ }^{a}$ MD, Assistant Professor, McAllen Family Medicine Residency Program, Department of Family and Community Medicine, University of Texas Health Science Center, San Antonio
\end{abstract}

It was an early morning on the first day of the year. I was scheduled to work my first 24-hour shift in an underserved medical facility in Ecuador. As a foreign physician, the attendings advised me to expect anything and a little bit of everything. The day started with a rush of adrenaline. I was sitting at the nurses' station when the first phone call of the shift was received. It was a from a government hospital calling to request a transfer. A pregnant woman had arrived at their hospital with significant vaginal bleeding, diagnosed with placenta previa. The government hospital was open for business, but without a surgeon or anesthesiologist they needed to transfer the patient to our facility.

She walked in and passed the nurses' station, smiling with her long black hair, young, strong, and ready to have her baby. Her family was walking behind her, happy and full of confidence. Without discussion, they walked directly to the operating room to prepare for the C-Section. The operating room was hot, humid, and very much available. All the helping hands arrived entirely energetic: a German General Surgeon, an American Anesthesiologist, and an Ecuadorian medical intern.

I continued working from the emergency area to the inpatient area, completing tasks as quickly and efficiently as possible. I returned to the nurses' station, looking at the time. "Something was wrong." I told myself. "Was I right? Had it been two hours since the team went into the operating room?" I exchanged thoughts with the attending. As we stood there, the phone rang. The nurse explained that the staff in the operating room was requesting blood. Our patient was in trouble.

After six hours of my first 24-hour shift in the beauty of the Andean Ecuador, I realized how the lack of resources, the acuity, and the number of the patients change your practice. In the midst of this Amazonian scene, this meant finding blood, somewhere, from somebody. The sole laboratory technician informed us there was not enough blood in the Red Cross bank; thus, the family members would become our primary donors.

As a resident physician, I did what I am trained to do best, continued seeing patients, aware of the time just by the brightness thru the windows. There, I did not need a pager, patients arrived at the doorway screaming and calling for help post celebration of New Year's Eve. The doors of the operating room opened, mom was intubated, and family members were crying in the hallway. They had many questions, but we had few answers. Their anguished faces lined the long white 
hallway, seeming to salute the intubated mother as she processed through the midst of them. We rushed to the patient, helping in whatever way we could: our hands helped the nurses, our minds helped the attendings and our souls, where were our souls? We were impersonal, concerned with fulfilling our duty; feelings and empathy were professionally suppressed.

The patient's black hair was pulled back and her eyes were shut. I realized the life of this young healthy mom had taken a turnaround. In the long hallway, the team of physicians explained to the family members that she had severe bleeding during surgery, and her uterus had been removed in hopes of saving her life. The team leader calmly explained the need for more blood. As he spoke, the family agreed to be tested as possible donors. "Please do everything to save her. It does not matter how much it costs." the family members shouted. The long night began. As the temperature dropped with the sunset, so did the patient's blood pressure. A dopamine drip was started. After a few hours, we reported to the attending: "Her blood pressure is not improving, there is no urine production, and her abdomen is inflated and hard." A long discussion took place between the attendings. Would taking this young mother to the operating room for a second time be the best decision? Would it mean giving the family false hopes? What about the staff and hospital resources? The patient was again taken to the operating room, the family crying and screaming in the hallway, begging God to deliver her from death: "It's too soon. She just became a mommy."

It was dark outside and hot inside. I continued to attend to my many responsibilities. One of the nurses told me they needed more hands in the operating room. As I changed and scrubbed, I thought, "OK, let me go and help, maybe my extra hands can be of some help." She was bleeding profusely. With my hands inside her abdominal cavity, I realized we could not stop the bleeding. What could we do? My hands were of no help, my mind understood what was happening, but my soul was far away. I could not connect emotionally or spiritually with this critically ill patient.

As I walked out of the operating room, the family was standing aligned in the hallway, looking into my eyes to find hope. "Please tell us doctor, how is she? You were able to save her, right?" I did not know what to say. My mind was present, but my soul was absent, unable to transcend the physical and temporal situation. The attending physician announced, "She continues to bleed."

The young mother was brought back to her room. The family entered quickly to accompany her. As I walked into her room, I found the family on their knees, singing with hands extended up towards the sky praying to God, awaiting a miracle. I looked at the patient, intubated. There were no more smiles on her face. Her hair was wet and her abdomen distended.

We were called at five in the morning. The nurses were concerned that the patient's clinical situation had worsened. We evaluated the patient and called the attending. We decided among ourselves not to perform any resuscitative measures. It was now the second day of the year. She would die in less than 24 hours. All of a sudden, my soul returns and speaks to me. Now, in full awareness of it, I am in shock. What has happened? What hope or comfort could I provide? My hands were of no help to the patient, so I left them behind. 
I asked myself: "Can you comfort their soul? How do you answer the family's why questions when you do not have answers?" Her family saw her as a mother, daughter, and sister. I had seen her as a patient. As I turned around, I saw my attending praying with the family, and I realized that I was not trained for this. I cannot reach the soul, but God can through us.

From life to death in less than 24 hours: do we really comprehend how fragile life is and become stronger physicians, able to live these and other stories? When we cannot stop death from visiting our patient, we can continue to be servants of God by comforting the souls of those remaining alive. I learned not only how vulnerable humans are, but also the importance of stopping our business to attend those left behind. After this experience I learned it is appropriate to ask family members if we can pray for them. It is at this moment that we recognize the need to provide comfort and reach their soul in time of pain. It is this time that we acknowledge the power of the Holy Spirit and our limitations as physicians.

Competing Interests: None declared.

Correspondence: Maria Colon-Gonzalez. colongonzale@uthscsa.edu

Cite this article as: Colon-Gonzalez M. Helping hands or comforting the soul? Christian Journal for Global Health (November 2014), 1(2):92-94. http://dx.doi.org/10.15566/cjgh.v1i2.43

(C) Colon-Gonzalez M. This is an open-access article distributed under the terms of the Creative Commons Attribution License, which permits unrestricted use, distribution, and reproduction in any medium, provided the original author and source are properly cited. To view a copy of the license, visit http://creativecommons.org/licenses/by/3.0/

www.cjgh.org 